L.M. Grigoryev

Analytical Center for the Government of the Russian Federation, National Research

University Higher School of Economics, Moscow, Russia

\title{
Social Inequality in the World - the Interpretation of Not-Evident Tendencies
}

Abstract. The inequality in the economy was different in different periods of economic development, within different political regimes, and depends on differences in the structure of society. The term is nowadays widely used - especially in political rhetoric - and almost always implies inequality of income distribution. Excessive income inequality distribution limits opportunities for economic growth of the country, for example, due to the increase in social inequality. Fluctuations in income from profits, shares, rents during crisis may temporarily reduce inequality, but the periods of prosperity naturally increase income inequality. Social inequality has a serious impact on economic growth and social stability in the country, but with a significant increase in income and consumption levels of the poor population in the XX-XXI centuries inequality in itself might not cause social unrest. Russia in the period of transformation has moved from a quasi-egalitarian society (in accordance with the parameters of inequality) to society, similar to the Latin American countries.

Keywords: wealth inequality, income inequality.

JEL Classification: D63.

Л.Н. Овчарова

нИу ВШЭ, Москва

Д.О. Попова

НИУ вШЭ, Москва

А.М. Рудберг

НИУ ВШЭ, Москва

\section{Аекомпозиция факторов неравенства доходов в современной России ${ }^{1}$}

Аннотация. За а последние 25 лет Россия из группы с низким неравенством переместилась в число стран с высоким уровнем дифференциации денежных доходов населения. Макроэкономический анализ показывает, что в основе этого процесса лежат различия в уровне оплаты труда, слабый выравнивающий әффект социальных трансфертов и появление таких новых источников доходов, как доходы от собственности и предпринимательский доход. До настоящего времени мы мало что знаем о факторах, определяющих дифференциацию денежных доходов на уровне домашних хозяйств. Декомпозиция неравенства в эквивалентных денежных расходах на межгрупповое и внутригрупповое на основе кроссекционных данных РМЭЗ-ВШЭ 1994-2014 гг. показывает, что на протяжении всего анализируемого периода одним из самых значимых факторов межгруппового неравенства в потреблении является регион проживания. В годы быстрого экономического роста увеличилась значимость межгруппового неравенства по образовательному уровню и интенсивности занятости, но в период экономической стагнации межгрупповая дифференциация по образовательному потенциалу домохозяйств стала снижаться. Несмотря на масштабную программу мер демографической политики, направленных на стимулирование рождаемости, наличие детей в семье в последние годы стало самым значимым фактором межгруппового неравенства. Регрессионный анализ детерминант неравенства, позволяющий оценить вклад признака в объясненную моделью дисперсию душевых расходов, позволил прийти к выводу, что в большей степени неравенство обусловлено меритократическими факторами. Вклад в общее неравенство фактора детской нагрузки не меняется последние десять лет, при этом выравнивающая роль присутствия в домохозяйстве пожилых постоянно усиливается.

Ключевые слова: неравенство в распределении доходов и заработной плать, богатство и бедность, человеческий капитал.

JEL Classification: D6, I3, J3, N00, P36.

\footnotetext{
${ }^{1}$ Статья подготовлена при финансовой поддержке Центра фундаментальных исследований НИУ ВШЭ.
} 
Тема дифференциации денежных доходов населения, актуализированная мировым кризисом 2008 г., завоевывает все большее пространство в научных и политических дискуссиях. Нобелевский лауреат Д.Ю. Стиглиц в своей книге (Stiglitz, 2012) отмечает основополагающий вклад в рост неравенства в США в последние 30 лет рентоориентированного поведения. В предисловии к этой книге он пишет о том, что «не только в Соединенных Штатах, но и во всем мире растет беспокойство, вызванное умножением неравенства и ограничением возможностей». Т. Пикетти в нашумевшей шестисотстраничной монографии (Пикетти, 2015 , с. 273) подчеркивает, что «история распределения богатства во все эпохи представляет собой ключ к пониманию страны в целом». Международный валютный фонд, традиционно акцентирующий внимание на неравенстве как основе формирования сбережений, трансформирующихся в инвестиции и новые рабочие места, в докладе за 2015 г. обращается к анализу негативного влияния неравенства на устойчивое развитие (Dabla-Norris et al., 2015). В этом же году ОЭСР выпускает доклад, где обсуждаются проблемы максимизации неравенства в денежных доходах в развитых странах за последние 30 лет (OECD, 2015). При этом результаты В. Гимпельсона и Д. Трейсмана (Gimpelson, Treisman, 2015) показывают, что фактическое соотношение доходов бедных и богатых и представления населения об этом, как правило, не совпадают; более того - субъективные оценки дифференцированы в разрезе социально-демографических и экономических групп. На основании этого авторы утверждают, что для анализа эффектов неравенства нужно ориентироваться не только на объективные, но и на субъективные измерения неравенства. В более ранних публикациях В.Е. Гимпельсон и Г.А. Монусова (Гимпельсон, Монусова, 2014) доказывали, что представления граждан о масштабе неравенства и его допустимости сильно варьируют, в зависимости, от того как люди оценивают существующие в обществе возможности доступа к каналам вертикального социального продвижения.

Вслед за Т. Пикетти мы прекрасно понимаем разницу между неравенством в трудовых доходах и доходах от капитала. Доходы от капитала, как правило, отличаются большей дифференциацией, но трудовые доходы, в свою очередь, составляют гораздо бо́льшую долю в общей структуре денежных поступлений домашних хозяйств. Не следует также забывать и о выравнивающей роли социальных транс- фертов. Влияние разных видов доходов на общую дифференциацию определяется вкладом в общий объем доходов, их распространением среди домашних хозяйств и дифференциацией по размеру.

Данные макростатистики позволяют получить представление об уровне дифференциации доходов и заработной платы и на основе данных о структуре доходов сформулировать некоторые предположения о детерминантах неравенства. Не будем останавливаться на обсуждении масштаба неравенства доходов в России, поскольку общепризнано (Овчарова, 2014; Модернизация России..., 2011) отнесение России к странам с высоким уровнем неравенства. Так, согласно последним официальным данным Росстата, индекс концентрации доходов Джини в 2014 г. составил $0,416^{2}$. Резкий рост неравенства зафиксирован в первые годы постсоветского развития, затем с 1995 г. наблюдался медленный рост, а в последние 10 лет - стабилизация на высоком уровне.

Официальные макроэкономические данные Росстата о структуре денежных доходов (табл. 1), полученные на основе баланса денежных доходов и расходов населения, свидетельствуют о том, что в среднем по сектору домашних хозяйств трудовые доходы были и остаются основным источником поступления денежных средств и именно их дифференциация должна задавать общий вектор динамики неравенства доходов. Вместе с тем, за годы постсоветского развития их доля несколько сократилась, что сопровождалось появлением доходов от собственности и предпринимательской деятельности. Гипотетически рост зна́чимости этих новых источников доходов должен способствовать росту неравенства. При этом за последние пять лет существенно увеличился вклад социальных трансфертов, призванных нивелировать доходное неравенство в разрезе доходных групп и этапов жизненного цикла семьи (табл. 1).

Более подробного комментария требуют макроэкономические данные о дифференциации заработной платы, поскольку, несмотря на ее главенствующий вклад в доходы населения, динамика дифференциации заработной платы и доходов в определенные периоды не совпадают (рис. 1). В первые годы постсоветского развития, как и в случае доходов, наблюдается резкий рост неравенства в оплате труда, который сменяется ростом с более низкими темпами. Однако после августовского кризиса 1998 г. сначала на фоне стабилизации дифференциации доходов наблюдается ускоренный

${ }^{2}$ См. материалы http://www.gks.ru/wps/wcm/connect/rosstat_main/rosstat/ru/statistics/population/level/\#. 
таблица 1

Структура денежных доходов населения России (макроданные), \%

\begin{tabular}{|c|c|c|c|c|c|c|c|}
\hline \multirow[b]{2}{*}{ Год } & \multirow{2}{*}{ 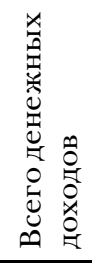 } & \multicolumn{6}{|c|}{ В том числе, \% } \\
\hline & & 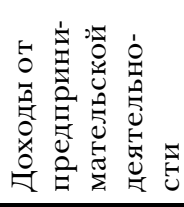 & 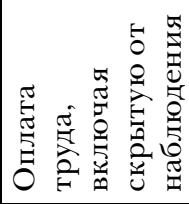 & 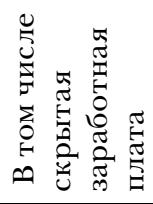 & 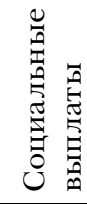 & 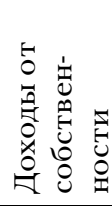 & 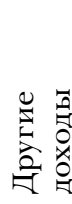 \\
\hline 1970 & 100 & 2,5 & 83,3 & - & 12,6 & 0,6 & 1,0 \\
\hline 1975 & 100 & 2,7 & 80,7 & - & 14,0 & 1,2 & 1,4 \\
\hline 1980 & 100 & 2,2 & 79,8 & - & 15,1 & 1,3 & 1,6 \\
\hline 1985 & 100 & 2,7 & 77,2 & - & 16,3 & 1,6 & 2,2 \\
\hline 1990 & 100 & 3,7 & 76,4 & - & 14,7 & 2,5 & 2,7 \\
\hline 1991 & 100 & 4,1 & 62,5 & - & 16,4 & 12,8 & 4,2 \\
\hline 1992 & 100 & 8,4 & 73,6 & - & 14,3 & 1,0 & 2,7 \\
\hline 1993 & 100 & 18,6 & 61,1 & - & 15,0 & 3,0 & 2,3 \\
\hline 1994 & 100 & 16,0 & 64,5 & - & 13,5 & 4,5 & 1,5 \\
\hline 1995 & 100 & 16,4 & 62,8 & 25,0 & 13,1 & 6,5 & 1,2 \\
\hline 1996 & 100 & 13,6 & 65,9 & 25,8 & 14,0 & 5,4 & 1,1 \\
\hline 1997 & 100 & 12,5 & 66,1 & 28,2 & 14,8 & 5,7 & 0,9 \\
\hline 1998 & 100 & 14,4 & 65,8 & 27,1 & 13,4 & 5,5 & 0,9 \\
\hline 1999 & 100 & 12,4 & 66,5 & 31,2 & 13,1 & 7,1 & 0,9 \\
\hline 2000 & 100 & 15,3 & 62,9 & 26,3 & 13,8 & 6,8 & 1,2 \\
\hline 2001 & 100 & 12,6 & 64,6 & 25,9 & 15,2 & 5,7 & 1,9 \\
\hline 2002 & 100 & 11,9 & 65,8 & 24,8 & 15,2 & 5,2 & 1,9 \\
\hline 2003 & 100 & 12,0 & 63,9 & 24,4 & 14,1 & 7,8 & 2,2 \\
\hline 2004 & 100 & 11,7 & 65,0 & 24,5 & 12,8 & 8,3 & 2,2 \\
\hline 2005 & 100 & 11,4 & 63,6 & 23,6 & 12,7 & 10,3 & 2,0 \\
\hline 2006 & 100 & 11,1 & 65,0 & 25,4 & 12,0 & 10,0 & 1,9 \\
\hline 2007 & 100 & 10,0 & 67,5 & 26,1 & 11,6 & 8,9 & 2,0 \\
\hline 2008 & 100 & 10,2 & 68,4 & 23,7 & 13,2 & 6,2 & 2,0 \\
\hline 2009 & 100 & 9,5 & 67,3 & 26,1 & 14,8 & 6,4 & 2,0 \\
\hline $2010^{*}$ & 100 & 8,9 & 65,2 & 24,9 & 17,7 & 6,2 & 2,0 \\
\hline 2011 & 100 & 8,9 & 65,6 & 25,6 & 18,3 & 5,2 & 2,0 \\
\hline 2012 & 100 & 9,4 & 65,1 & 23,8 & 18,4 & 5,1 & 2,0 \\
\hline 2013 & 100 & 8,6 & 65,3 & 23,9 & 18,6 & 5,5 & 2,0 \\
\hline 2014 & 100 & 8,4 & 65,8 & 24,2 & 18,0 & 5,8 & 2,0 \\
\hline $2015^{* *}$ & 100 & 7,3 & 65,9 & - & 18,2 & 6,6 & 2,0 \\
\hline
\end{tabular}

Источники: Социальное положение..., 1999-2015; Российский статистический ежегодник за 2010-2015 гг.

Примечание. Символом «" Республике; «** - расчет по оперативным данным. 
рост дифференциации заработной платы, а с 2002 г. медленный рост и стабилизация неравенства доходов сопровождаются резким снижением неравенства заработных плат.

Получается, что эти данные не подтверждают гипотезы об определяющем влиянии заработной платы на неравенство в оплате труда, поскольку динамика этих показателей может быть разнонаправленной. Однако справедливо и другое утверждение: официальные данные не могут использоваться для оценки влияния дифференциации в заработной плате на неравенство доходов, поскольку они характеризуют ограниченный сектор занятости. Публикуемые Росстатом оценки базируются только на данных о наблюдаемой заработной плате в апреле и только на крупных и средних предприятиях. Согласно данным в табл. 1 практически треть фонда оплаты труда скрыта от статистического наблюдения, при этом доля занятых на крупных и средних предприятиях постоянно сокращается. Так, с 2004 по 2012 г. этот сегмент рынка труда потерял 4,5 млн человек (Социальная политика..., 2015), а в ноябре 2015 г. к нему относились только 33 млн человек, или $45,8 \%$ штатных работников без учета совместителей (Социально-экономическое положение России..., 2016). Апрельские данные по заработной плате также не учитывают дифференцирующий эффект переменной части за- работной платы, выплачиваемой в конце квартала или года.

Принимая во внимание ограниченную представительность макрооценок неравенства в оплате труда, можно сделать вывод о том, что важными факторами неравенства заработных плат являются межотраслевая и внутриотраслевая дифференциация. В более ранних публикациях (Овчарова, 2003) мы уже показывали, что в основе роста дифференциации заработной платы в первые годы после августовского кризиса лежал рост средней заработной платы в конкурентоспособных отраслях и трудовых доходов руководителей в низкооплачиваемых секторах экономики. Данные на рис. 2-3 показывают, что последующее снижение общей дифференциации заработной платы на крупных и средних предприятиях происходило за счет сокращения межотраслевых различий и более высокого роста заработной платы в сегменте низкооплачиваемых должностей.

Эффекты влияния на дифференциацию неформальной оплаты труда, занятости на малых и микропредприятиях могут быть выявлены только на основе данных выборочных обследований населения и домашних хозяйств. Первичные кроссекционные данные на эту тему широко представлены в обследовании домохозяйств «Российский мониторинг экономического положения и здоровья населения

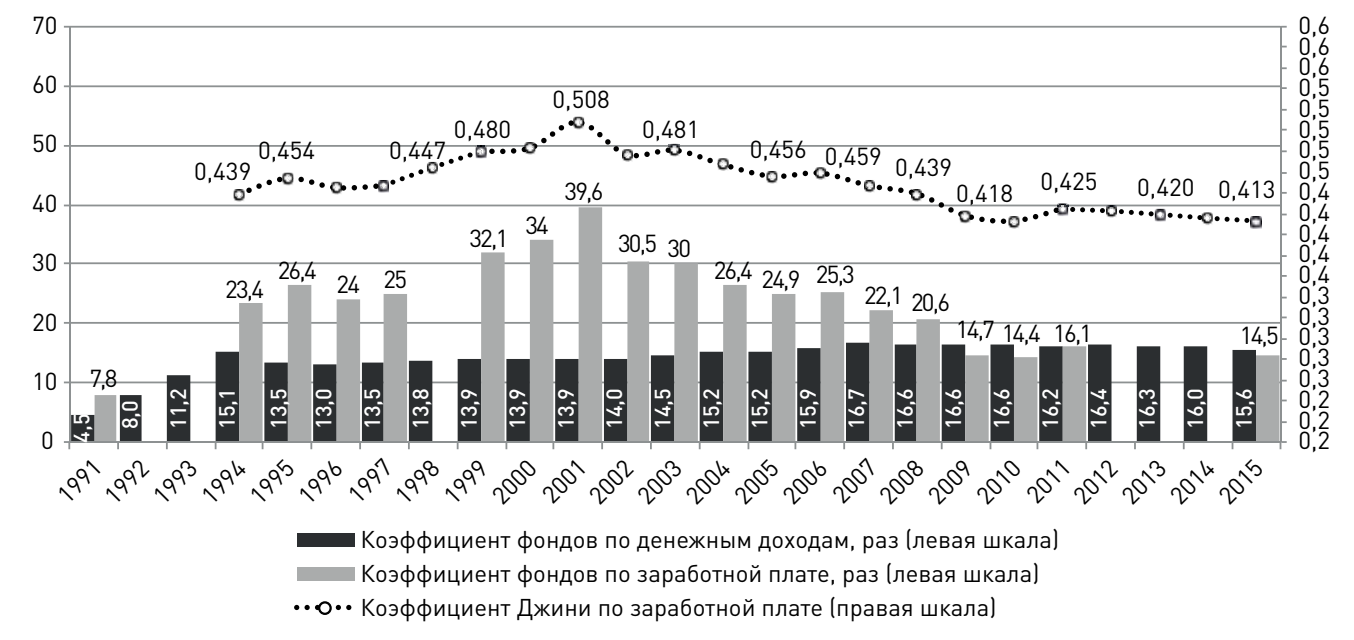

Pис. 1

Коэффичиенты дифференииачии доходов и заработной плать

Источник: Российский статистический ежегодник за 2010-2015 гг.

\footnotetext{
${ }^{3}$ РМЭЗ-ВШЭ - негосударственное лонгитюдное ежегодное обследование домохозяйств «Российский мониторинг экономического положения и здоровья населения НИУ ВШЭ» (с 1994 г.) - общенациональные репрезентативные опросы на базе вероятностной стратифицированной многоступенчатой территориальной выборки, разработанные при участии ведущих мировых экспертов в этой области. Ежегодная выборка составляет 8 тыс. частных домохозяйств (см. http://www.cpc.unc.edu/projects/rlms и http://www.hse.ru/rlms).
} 


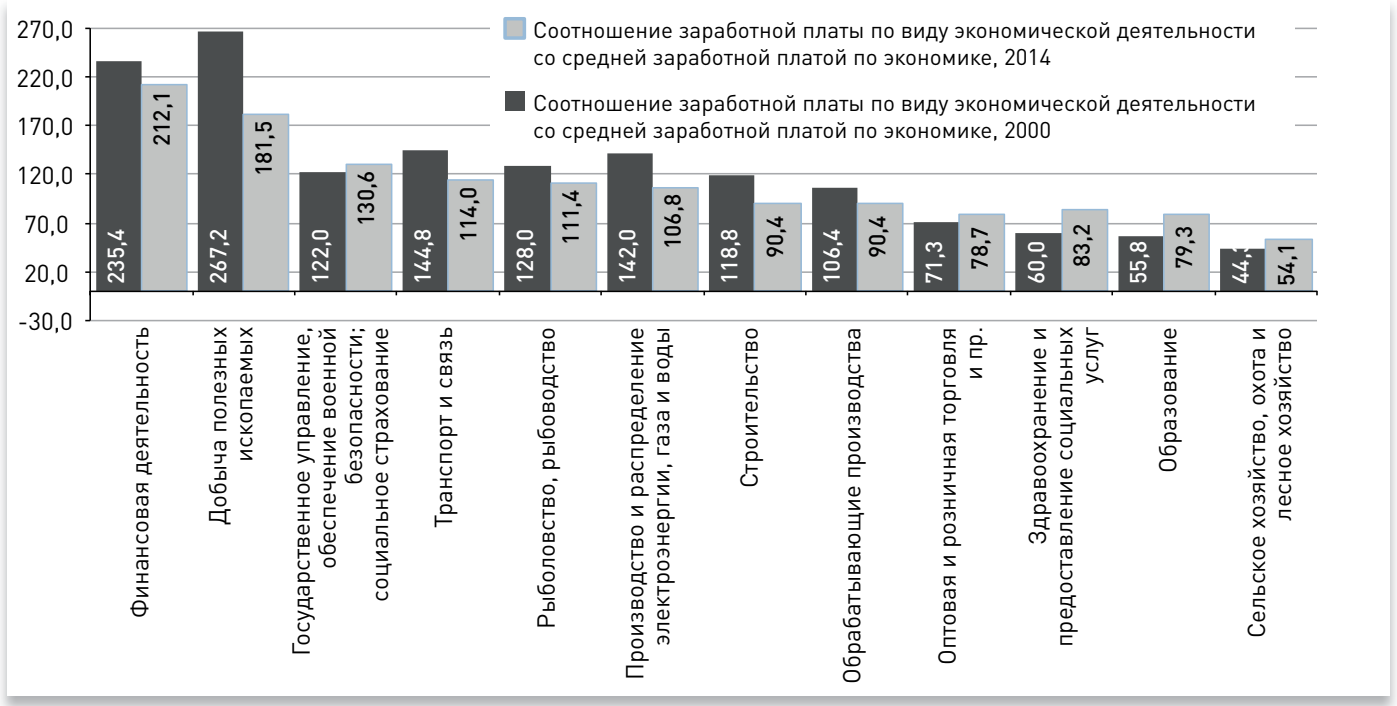

Puc. 2

Соотношение средней заработной платы по виду экономической деятельности со средней заработной платой по экономике в челом, \%, данные по крупным и средним предприятиям

Источник: по данным Росстата.

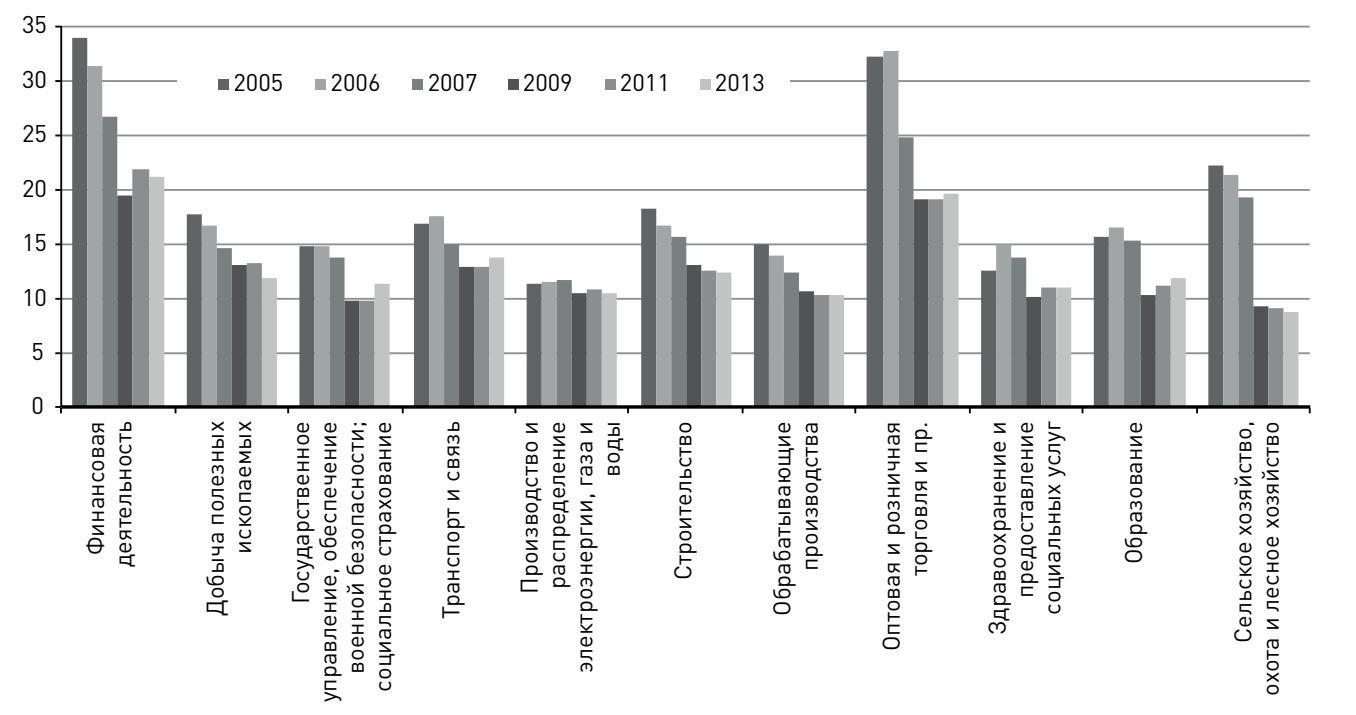

Рис. 3

Коэффиииент дифференииачии фондов заработной платы в разрезе основных видов экономической деятельности, раз (данные по крупным и средним предприятиям)

Источник: по данным Росстата.

НИУ ВШЭ» (РМЭЗ-ВШЭ)ํ. В тех случаях, когда выборки данного обследования недостаточно для оценки одномоментных событий, мы будем обращаться к проводимому Росстатом выборочному наблюдению доходов населения и участия в социальных программах (ВНДН $)^{4}$,

\footnotetext{
${ }^{4}$ Выборочное наблюдение доходов населения и участия в социальных программах (ВНдН) организуется во всех субъектах РФ с охватом в 2015 г. 45 тыс. частных домашних хозяйств и более 106 тыс. индивидов в целях получения статистической информации, отражающей роль оплаты труда, доходов от самостоятельной занятости и собственности, пенсий и социальных пособий в обеспечении материального благосостояния семей. Всего проведено три раунда и получена информация о доходах за 2011, 2013 и 2014 г. (см. http://www.gks.ru/free_doc/new_site/vndn-2015/index.html).
} 
выборка которого в 2015 г. охватила 45 тыс. частных домохозяйств, а информация о доходах характеризует предыдущий год.

Проблема всех выборочных обследований населения состоит в том, что они в неполной мере охватывают высокодоходные слои населения. Действительно, согласно официальным данным Росстата в 2014 г. среднедушевые доходы составили 27767 руб. (Социальное положение..., 2015), а по данным ВНДН - 24503 руб. (расчеты авторов), или $88 \%$ макроэкономической оценки. Вместе с тем, оценки средней заработной платы достаточно близки: 32495 руб. и 32358 руб. соответственно. Это означает, что в обследовании плохо улавливаются незарплатные виды доходов (предпринимательский доход и доходы от собственности), а большая часть заработков учтена в полном объеме. Наши оценки на базе ВНДН за 2014 г. показывают рост неравенства в заработных платах на $12 \%$ при переходе от заработной платы формально занятых (коэффициент дифференциации фондов 13,8) к экономике в целом, включая неформальную занятость (коэффициент дифференциации фондов 15,4). При этом добавление скрытой экономики смещает распределение в сторону более низких заработков: средняя заработная плата в ненаблюдаемом сегменте составила 21836 руб., или $64 \%$ средней заработной платы по всем занятым, максимальная концентрация неформально занятых наблюдается в двух первых децильных группах, а в последней они практически не представлены. Эффект влияния малого бизнеса в случае ВНДН присутствует, но мы не можем его выделить, так как не знаем размер предприятия, на котором заняты работники.

Данные РМЭЗ-ВШЭ из-за ограниченного объема не дают возможности получить надежные оценки, но позволяют высказать гипотезу о том, что влияние малого бизнеса на распределение по заработной плате усиливает группу малообеспеченных, оно практически не представлено в середине распределения и незначительно усиливает группу высокооплачиваемых. Итоги сплошного федерального статистического наблюдения над деятельностью субъектов малого и среднего предпринимательства за 2010 г. (Итоги сплошного федерального статистического наблюдения..., 2012) подтверждают это оценками отношения средней заработной платы в малом бизнесе и по экономике в целом: средняя заработная плата на малых предприятиях в наблюдаемом году составила 12367 руб., или 59\% средней по экономике. Большее по сравнению с неформальной занятостью отклонение средней заработной платы в сторону меньших значений и зафиксированное РМЭЗ-ВШЭ представительство этого сектора среди высокооплачиваемых позволяет предположить, что по сравнению с неформальной занятостью малый бизнес еще больше усиливает неравенство в оплате. Таким образом, последние 15 лет низкооплачиваемая занятость не исчезала, а выталкивалась за пределы крупных и средних предприятий в зону неформальной занятости и малого бизнеса, поэтому реальное неравенство аналогично тому, которое складывалось накануне кризиса 1998 г.: по фондовому коэффициенту дифференциации 24-25 раз.

Данные обследований также позволяют провести декомпозицию факторов неравенства доходов и заработной платы на индивидуальном уровне. Здесь в первую очередь следует отметить неоднократно опубликованные результаты А. Лукьяновой, полученные на базе РМЭЗ-ВШЭ. На данных за 1998-2005 гг. (Гимпельсон и др., 2008, с. 528-535) А. Лукьянова показала, что за межотраслевыми и внутриотраслевыми различиями скрывается межрегиональное неравенство и влияние человеческого капитала (образование и профессия). В своих более поздних публикациях А. Лукьянова доказала, что в 1994-2003 гг. в российской экономике отраслевое неравенство, очищенное от влияния демографических и географических характеристик, фактора человеческого капитала и типа занятости, объясняло 7,5-12\% вариации заработных плат у мужчин и 5-10\% у женщин (Lukiyanova, 2008). Эту компоненту неравенства следует рассматривать как неравенство возможностей.

Сила влияния заработной платы, как, впрочем, и других источников доходов, на общее неравенство трансформируется в процессе перехода от индивидуальных доходов к среднедушевым по домашнему хозяйству. Доступность отдельных источников доходов только для узких адресных групп получателей способна существенно повлиять на масштабы неравенства. Для понимания распространения отдельных источников доходов среди домохозяйств также обратимся к данным обследований домашних хозяйств. Преимущества здесь у данных ВНДН - они отличаются большим объемом выборки.

Согласно результатам дескриптивного анализа, представленного на рис. 4 и в табл. 2, более $80 \%$ домохозяйств имеют доходы от трудовой деятельности и социальные трансферты, и только $12 \%$ - доходы от собственности. Получатели заработных плат и доходов от собственности смещены в сторону наиболее обеспеченных, а получатели социальных 


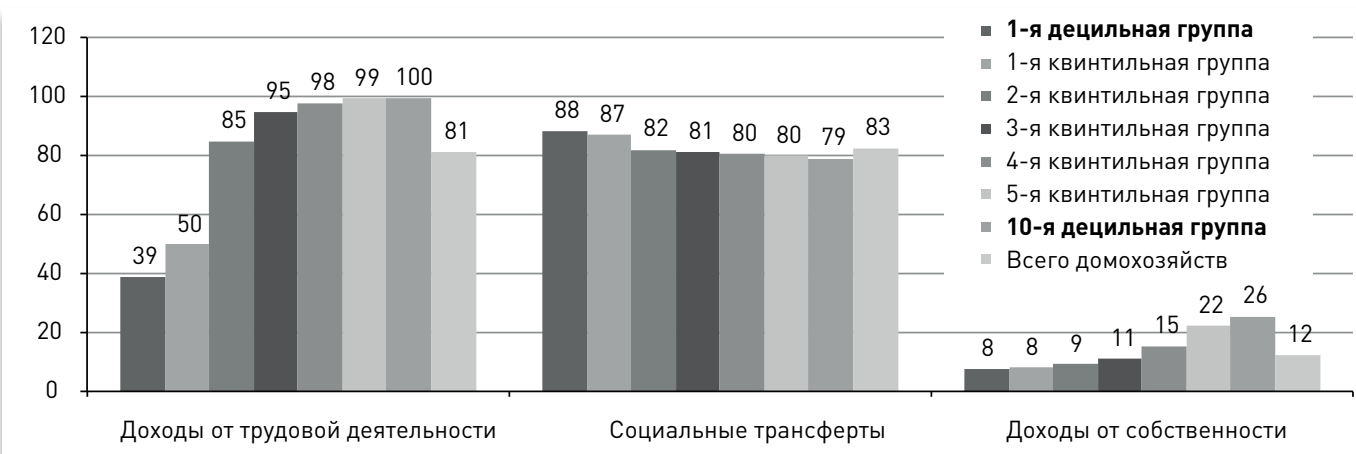

Puc. 4

Представительство домохозяйств, имеющих доходы от трудовой деятельности, сочиальнье трансферты и доходы от собственности, в различных доходнъх группах (2014 г.), \% числа домохозяйств доходной группь

Источник: расчеты авторов на основе данных ВНДН-2015.

трансфертов представлены в доходах всех рассматриваемых групп. Если принять во внимание вклад данных источников в совокупные доходы получателей, то становится очевидной доминирующая роль социальных трансфертов в доходах 10 и 20\% самых бедных. Для остальных доходных групп основным источником доходов является заработная плата.

Данные в табл. 2 показывают, что нам удалось собрать информацию только о небольших размерах доходов от собственности, которые в совокупности составляют 1,3\% всех денежных доходов. Макроэкономические данные баланса денежных доходов и расходов (см. табл. 1) в 2014 г. оценивают вклад данного источника доходов на уровне $5,8 \%$. Следовательно, мы не можем измерить вклад доходов от собственности в общее неравенство по доходам. Можно предположить, что их учет в полном объеме привел бы к росту неравенства.

Несмотря на то что выборочные обследования населения не содержат данных о высоких доходах, особенно когда речь идет о незарплатных источниках, только они позволяют провести декомпозицию неравенства доходов на индивидуальном уровне. В данной методологии анализа классический подход к изучению факторов неравенства заключается в декомпозиции агрегированных индексов неравенства по подгруппам населения. Если рассматривать весь имеющийся набор доходов как совокупность, где подгруппами являются группы индивидов, выделенные на основе какого-либо признака, можно разложить общее неравенство доходов на неравенство между этими подгруппами и неравенство внутри подгрупп. Например, используя этот метод, можно оценить, какой вклад в общее неравенство вносят различия внутри и между занятыми в разных секторах әкономики или городскими и сельскими жителями. Некоторые индексы неравенства, например меры, принадлежащие к классу обобщенной энтропии (энтропийные индексы Тейла), без остатка раскладываются на внутри- и межгрупповую компоненты неравенства (Shorrocks, 1980, 1984). Последняя интерпретируется как вклад данного фактора в общее неравенство. Эта методика уже неоднократно использовалась при исследовании факторов неравенства в России на микроуровне (Kislitsina, 2003; Yemtsov, 2003; Popova, 2013). В русскоязычной литературе данные инструменты измерения неравенства достаточно подробно описаны в коллективной монографии наших коллег из НИУ ВШЭ (Гимпельсон и др., 2008, с. 538-546).

С 1994 г. на основе данных РМЭЗ-ВШЭ мы ведем наблюдение за динамикой межгруппового неравенства на основе декомпозиции, где используются энтропийные индексы неравенства (Generalised Enthropy Class). Данная методология, используемая в целях нашего исследования, подробно была представлена на XVI Апрельской международной научной конференция «Модернизация экономики и общества» НИУ ВШЭ (Попова, 2015). В отличие от всех остальных индексов неравенства, включая индекс Джини, энтропийные индексы неравенства могут четко раскладываться на межгрупповую и внутригрупповую компоненты, которые в сумме будут равны значению агрегированного индекса. Следовательно, мы можем сделать вывод, что часть общего неравенства объясняется неравенством между подгруппами населения, а оставшаяся часть - неравенством внутри этих подгрупп. Например, если разбить 
Таблица 2.

Вклад в совокупные денежные доходы домохозяйств доходов от трудовой деятельности, социальных трансфертов и доходов от собственности в разрезе доходных групп (данные ВНДН, 2014 г.), \%

\begin{tabular}{|c|c|c|c|c|c|c|c|c|}
\hline \multirow{2}{*}{ 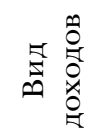 } & \multirow[b]{2}{*}{ Доходная группа } & \multirow{2}{*}{$\begin{array}{c}\text { Нет } \\
\text { таких } \\
\text { доходов }\end{array}$} & \multicolumn{5}{|c|}{ Доля в совокупных доходах домохозяйств } & \multirow[b]{2}{*}{ Итого } \\
\hline & & & $\begin{array}{c}\text { менее } \\
20 \%\end{array}$ & $20-40 \%$ & $40-60 \%$ & $60-80 \%$ & $\begin{array}{c}\text { более } \\
80 \%\end{array}$ & \\
\hline \multirow{8}{*}{ 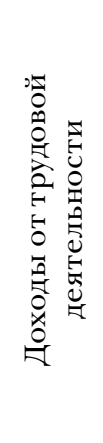 } & Децильная 1 & 61,1 & 4,0 & 4,1 & 4,6 & 4,4 & 21,8 & 100 \\
\hline & Квинтильная 1 & 50,3 & 4,1 & 4,9 & 7,6 & 6,7 & 26,4 & 100 \\
\hline & Квинтильная 2 & 15,2 & 3,0 & 7,2 & 12,7 & 18,1 & 43,8 & 100 \\
\hline & Квинтильная 3 & 5,2 & 2,2 & 6,3 & 12,4 & 20,1 & 53,8 & 100 \\
\hline & Квинтильная 4 & 2,2 & 1,6 & 3,7 & 10,6 & 20,7 & 61,2 & 100 \\
\hline & Квинтильная 5 & 0,8 & 1,0 & 2,8 & 4,8 & 17,0 & 73,6 & 100 \\
\hline & Децильная 10 & 0,4 & 1,1 & 2,0 & 2,3 & 12,8 & 81,4 & 100 \\
\hline & $\begin{array}{l}\text { Все } \\
\text { домохозяйства }\end{array}$ & 18,8 & 2,6 & 5,1 & 9,6 & 15,6 & 48,3 & 100 \\
\hline \multirow{8}{*}{ 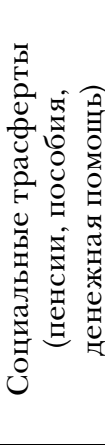 } & Децильная 1 & 11,8 & 10,3 & 4,3 & 4,6 & 4,2 & 64,8 & 100 \\
\hline & Квинтильная 1 & 13,1 & 13,5 & 6,8 & 7,6 & 5,0 & 54,0 & 100 \\
\hline & Квинтильная 2 & 18 & 26,0 & 18,2 & 12,8 & 7,2 & 17,8 & 100 \\
\hline & Квинтильная 3 & 19 & 35,3 & 20,1 & 12,2 & 6,2 & 7,2 & 100 \\
\hline & Квинтильная 4 & 19,6 & 42,6 & 20,4 & 10,1 & 3,7 & 3,6 & 100 \\
\hline & Квинтильная 5 & 20,2 & 55,2 & 15,8 & 4,5 & 2,6 & 1,7 & 100 \\
\hline & Децильная 10 & 21 & 62,4 & 11,1 & 2,1 & 2,0 & 1,4 & 100 \\
\hline & $\begin{array}{l}\text { Все } \\
\text { домохозяйства }\end{array}$ & 17,4 & 31,6 & 15,3 & 9,5 & 5,1 & 21,1 & 100 \\
\hline \multirow{8}{*}{ 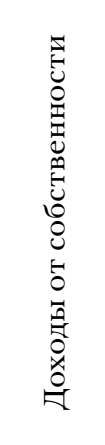 } & Децильная 1 & 92,5 & 7,1 & 0,3 & 0,0 & 0,0 & 0,1 & 100 \\
\hline & Квинтильная 1 & 92 & 7,6 & 0,3 & 0,0 & 0,1 & 0,0 & 100 \\
\hline & Квинтильная 2 & 90,9 & 8,6 & 0,4 & 0,1 & 0,0 & 0,0 & 100 \\
\hline & Квинтильная 3 & 89,1 & 10,6 & 0,2 & 0,1 & 0,0 & 0,0 & 100 \\
\hline & Квинтильная 4 & 84,6 & 15,0 & 0,3 & 0,1 & 0,0 & 0,0 & 100 \\
\hline & Квинтильная 5 & 78,0 & 21,7 & 0,2 & 0,1 & 0,0 & 0,0 & 100 \\
\hline & Децильная 10 & 74,4 & 25,4 & 0,2 & 0,0 & 0,0 & 0,0 & 100 \\
\hline & $\begin{array}{l}\text { Все } \\
\text { домохозяйства }\end{array}$ & 87,8 & 11,8 & 0,3 & 0,1 & 0,0 & 0,0 & 100 \\
\hline
\end{tabular}

все домохозяйства на две любые группы, общее неравенство можно разложить на неравенство между этими группами и на неравенство внутри каждой из них. Графики на рис. 5 показывают, что динамика показателей неравенства, полученных на основе данных РМЭЗ-ВШЭ, аналогична макроэкономическим данным, хотя масштаб неравенства выше.

Наша зависимая переменная - реальные душевые денежные расходы, которые равны сумме всех денежных расходов домохозяйства за месяц, предшествующий интервью. Выбор расходов, а не доходов, обусловлен меньшими сезонными колебаниями данного показателя и ранее доказанной большей достоверностью для оценки текущего потребления (Овчарова, 2009). Для панельного анализа показатель расходов был дефлирован и выражен в ценах 1994 г.

В качестве независимых переменных используется набор категориальных переменных, позволяющих оценить относительный вклад различных групп домохозяйств в общее неравенство расходов. Мы исходим из того, 


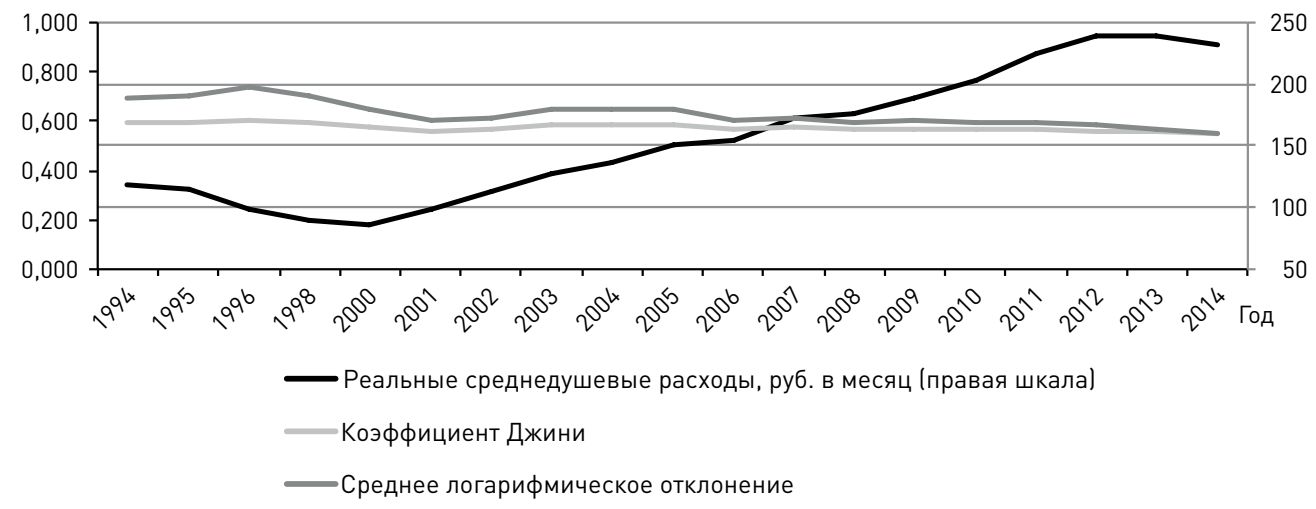

Pис. 5

Динамика реальных среднедушевых доходов (в иенах 1994 г.) и неравенства в 1994-2014 г2. Истоиник: расчеты авторов на перевзвешенных кроссекционных данных РМЭЗ-ВШЭ 1994-2014 гг.

Примечание. Среднедушевые денежные расходы, сглаженный временной ряд.

что уровень денежных расходов домохозяйств определяется их демографической структурой (число взрослых и детей, пол и возраст членов домохозяйства), человеческим капиталом (уровень образования и статус занятости членов домохозяйства) и внешними факторами, связанными с местом проживания. Из тестируемых характеристик в список анализируемых были включены те, для которых межгрупповое неравенство хотя бы на одной временной точке принимает на себя не менее $5 \%$ общего неравенства:

- гендерный состав (соотношение числа взрослых женщин и мужчин);

- нагрузка пожильми (отношение числа индивидов в возрасте 65 лет и старше и индивидов в возрасте 18-64 лет);

- детская нагрузка (отношение числа детей до 18 лет и взрослых в возрасте 18-64 лет);

- уровень образования (отношение числа взрослых с высшим и без высшего образования);

- статус занятости (отношение числа занятых и незанятых взрослых ${ }^{5}$ );

- тип поселения;

- регион проживания.

Результаты статической декомпозиции представлены на рис. 6. В качестве зависимой переменной используется среднее логарифмическое отклонение (энтропийная мера неравенства $G E(\alpha)$ с параметром $\alpha=0)$. Отметим, что данный индекс более чувствителен к изменениям неравенства на нижнем отрезке распределения доходов.
Важно также подчеркнуть, что в данном случае мы используем российскую традицию анализа микроданных о благосостоянии, в соответствии с которой на индивидуальном уровне среднедушевые характеристики определяются путем деления совокупного семейного ресурса на число членов домохозяйства: стандартный душевой доход, расход или потребление. Но в мировой практике корректным считается использование эквивалентных доходов, расходов или потребления, учитывающих экономию на размере семьи, в основе которой лежит эффект совместного потребления неиндивидуальных товаров длительного пользования (Deaton, 1997; Овчарова, 2009). С конца 1990-х годов Евростат начал использовать модифицированную шкалу ОЭСР, согласно которой главе домохозяйства присваивается вес, равный единице; 0,5 - для каждого последующего взрослого члена домохозяйства; 0,3 - для каждого ребенка (OECD, 2013). Вклад межгрупповой компоненты в общее неравенство на основе эквивалентных расходов по модифицированной шкале ОЭСР представлен на рис. 7. Переход к эквивалентным расходам меняет значимость и соотношение межгрупповых детерминант неравенства. В частности, они сглаживают эффекты, обусловленные демографическими характеристиками домашних хозяйств.

Какие выводы относительно детерминант неравенства на индивидуальном уровне мы можем сделать? В первую очередь отметим, что до 2002 г. регион проживания был самым мощным фактором межгруппового неравенства. Использование эквивалентных расходов

\footnotetext{
${ }^{5}$ Категория «незанятый» включает безработных и экономически неактивных.
} 


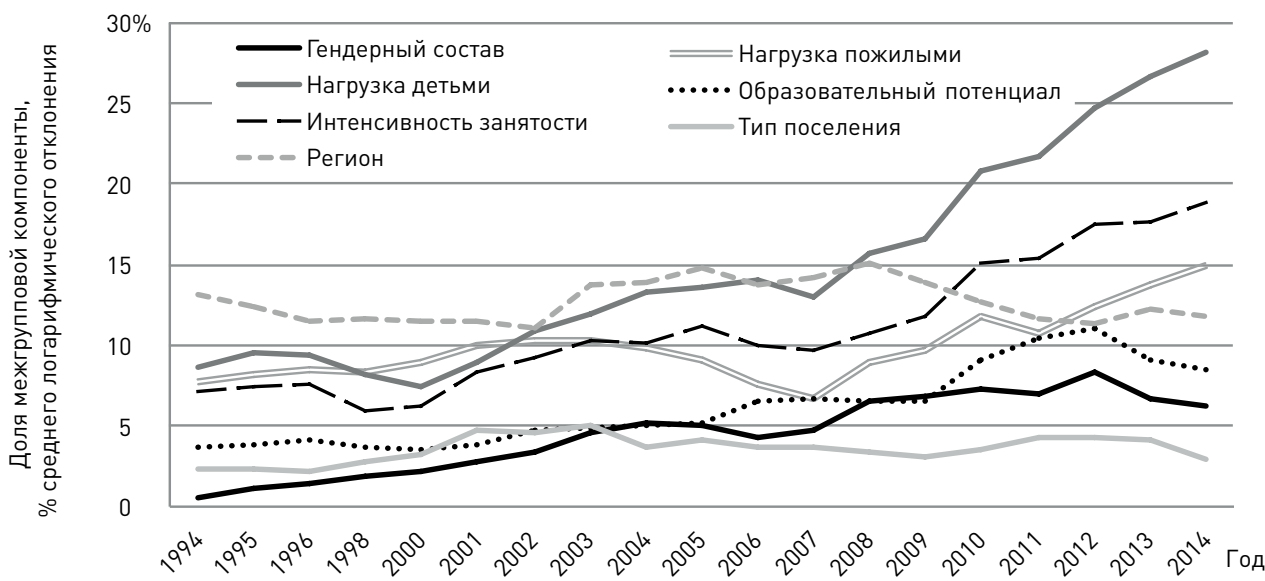

Pис. 6

Детерминанты неравенства в 1994-2014 г2. (вклад межгрупповой компоненты в общее неравенство, среднее логарифмическое отклонение)

Источник: расчеты авторов на перевзвешенных кроссекционных данных РМЭЗ-ВШЭ 1994-2014 гг.

Примечание. Среднедушевые денежные расходы, сглаженный временной ряд.

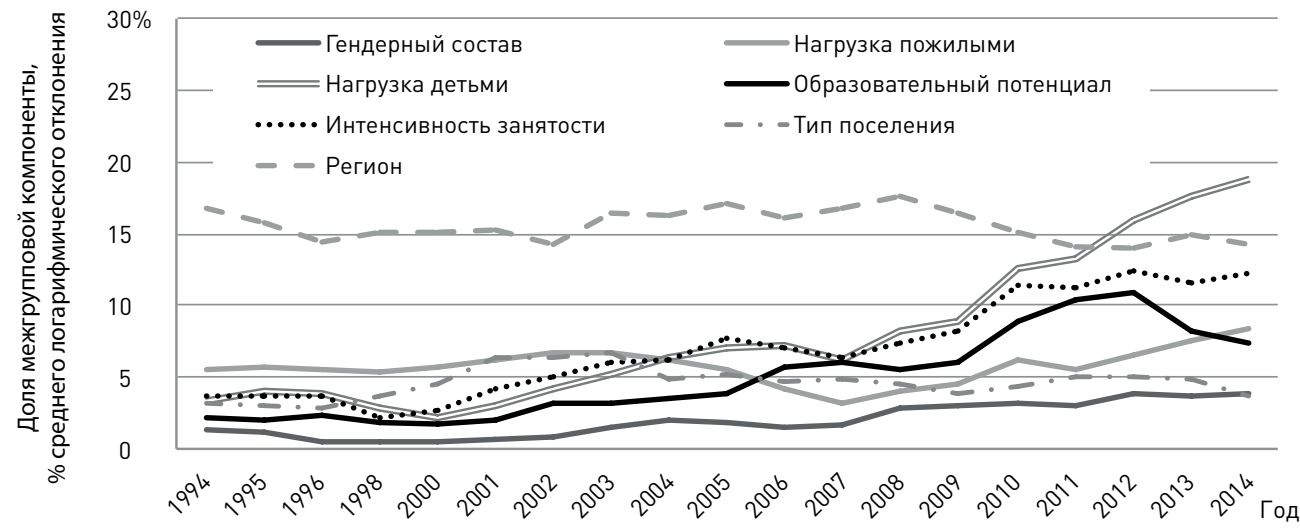

Pис. 7

Детерминанты неравенства в 1994-2014 г2. (вклад межгрупповой компоненты в общее неравенство, среднее логарифмическое отклонение)

Источник: расчеты авторов на перевзвешенных кроссекционных данных РМЭЗ-ВШЭ 1994-2014 гг.

Примечание. Эквивалентные денежные расходы (модифицированная шкала ОЭСР), сглаженный временной ряд.

только усилило его значимость и превосходство над другими факторами на этом временном интервале. Значимость данного фактора незначительно менялась с течением времени синхронно с динамикой цен на нефть. В полученном результате отображается устойчивая рентоориентированная структура российской экономики и концентрация конкурентоспособных отраслей в определенных регионах.
Другие факторы неравенства стали набирать силу после августовского кризиса 1998 г., что особенно заметно в случае использования стандартных душевых расходов, согласно которым, начиная с 2007 г., самым значимым фактором неравенства стало соотношение числа детей и взрослых в домашнем хозяйстве. В 2014 г., когда данный фактор был лидером межгруппового неравенства, эта 
характеристика домашних хозяйств объясняла практически $30 \%$ всего неравенства. Важно подчеркнуть, что ускоренный рост межгруппового неравенства по уровню детской нагрузки начался после того, когда в 2007 г. был принят пакет мер стимулирования рождаемости (материнский капитал, повышение пособия по уходу за ребенком, компенсационные доплаты за пребывание детей в детских дошкольных учреждениях и пр.). Получается, что население, включая низкодоходные слои, откликнулось на принятые меры, что подтверждают показатели рождаемости. Однако предложенная поддержка оказалась недостаточной, и в результате мы видим рост неравенства, обусловленный числом детей в семье: семьи без детей равномерно богатели, а семьи, где соотношение взрослых и детей выше 1,1, равномерно беднели (рис. 8). Это означает, что стимулирующая роль данных мер политики будет быстро исчерпана. Даже при переходе к эквивалентной шкале расходов, максимально учитывающей әффект от совместного проживания в домохозяйстве, детская нагрузка остается самым значимым фактором неравенства, хотя его дифференцирующая сила снижается.

Особого внимания заслуживает рост значимости таких меритократических факторов неравенства, как «интенсивность занятости» и «образовательный потенциал». В случае эквивалентных расходов они еще не достигают дифференцирующей мощи фактора «регион проживания», но в варианте стандартных душевых расходов «занятость» обогнала пара- метр «регион проживания». Межгрупповое неравенство по уровню образования, которое медленно увеличивалось на этапе высоких темпов экономического роста, стало быстро набирать рост после кризиса 2008 г. и снизило свою значимость на этапе стагнации. За ростом дифференцирующей силы соотношения пожилых и трудоспособных членов домашнего хозяйства стоит обеднение неработающих пенсионеров и рост доходов работавших пенсионеров.

В целом данные на рис. 6 и 7 позволяют выделить три группы факторов межгрупповой дифференциации расходов российских домохозяйств: 1) региональная неоднородность размещения рентопроизводящих отраслей; 2) меритократическое неравенство, обусловленное качеством человеческого капитала; 3) неравенство, формируемое недостаточной выравнивающей силой социальной политики, особенно в отношении семей с детьми.

Используя классический метод декомпозиции, невозможно оценить относительный вклад нескольких переменных одновременно, поэтому обратимся к регрессионному методу, позволяющему оценить совместный әффект различных факторов неравенства на микроуровне. Обратимся к методике декомпозиции неравенства на основе регрессионного анализа, предложенной в работе (Morduch, Sicular, 2002). Основная идея заключается в разложении совокупного дохода $Y$ в регрессионное уравнение

$$
Y=X \beta+\varepsilon,
$$

где $X-(n \times M)$-вектор признаков; $\varepsilon-(n \times 1)$-век-

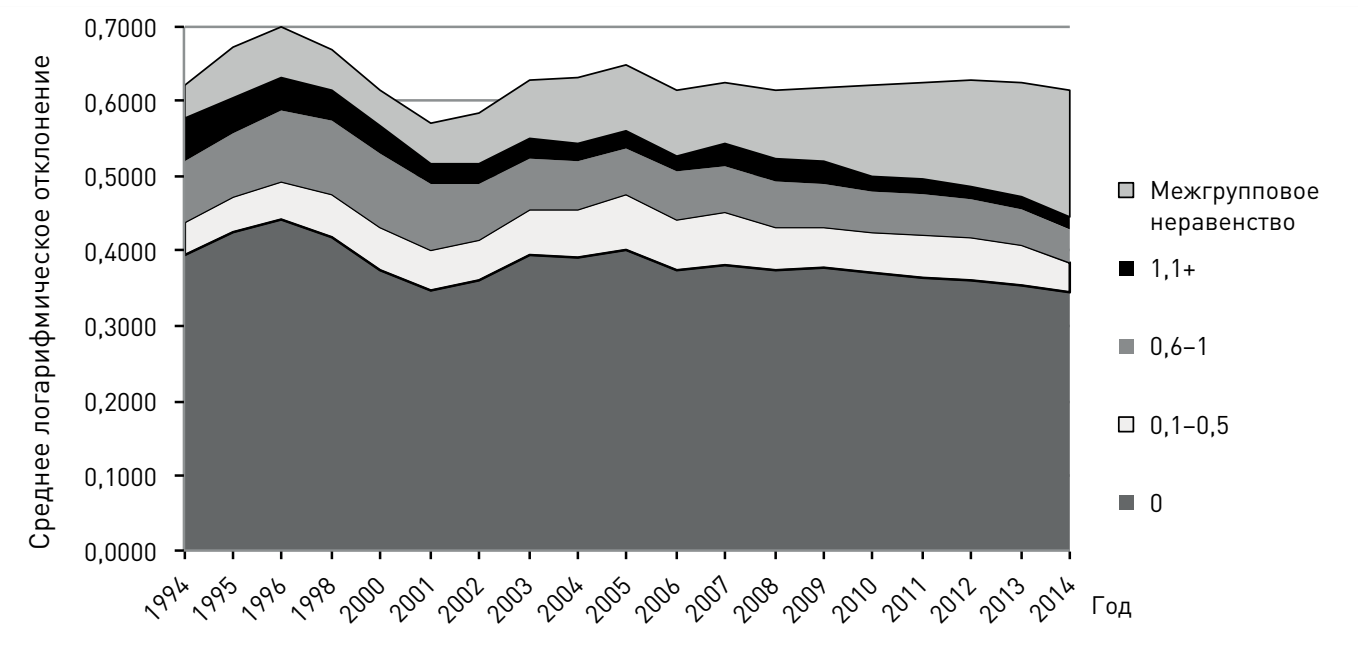

Pис. 8

Декомпозичия индекса Тейла GE(O) для фактора детской нагрузки

Источник: расчеты авторов на перевзвешенных кроссекционных данных РМЭЗ-ВШЭ 1994-2014 гг.

Примечание. Эквивалентные денежные расходы (модифицированная шкала ОЭСР), сглаженный временной ряд. 
тор остатков. Следующий шаг заключается в разложении каждой единицы $i$ совокупного дохода на компоненты $Y_{i}^{m}$, объясненные каждой независимой переменной $\beta_{i}$ в соответствии с

$$
Y_{i}=\sum_{m=1}^{M+1} Y_{i}^{m},
$$

где $Y_{i}^{m}=X_{i}^{m} \beta^{m}$ для $m=1, \ldots, M ; Y_{i}^{m}=\varepsilon_{i}$ для $m=M+1$. Этот подход предполагает, что детерминистская часть модели объясняет всю вариацию дохода, потому что по определению остатки являются чистыми и не влияют на форму оцененной функции распределения доходов.

Как и в случае анализа межгруппового неравенства, мы обратились к данным РМЭЗ-ВШЭ. Низкая репрезентативность переменной «регион проживания» существенно ухудшала качество модели, поэтому в данном анализе она была исключена. На рис. 9 показаны средние доли расходов $\hat{B}_{m}\left(\bar{X}_{m} / \bar{y}\right)$, которые объясняют каждый признак и рассчитываются как произведение среднего значения каждой переменной на ее оцененный коэффициент из уравнения расходов. Применение регрессионного анализа позволяет оценить относительный эффект всех детерминант неравенства одновременно.
При включении всех факторов сегодня в России наиболее влиятельным является уровень образования членов домохозяйства. Вес этого фактора в объяснении неравенства душевых расходов составлял около 34-36\% как в начале рассматриваемого периода (1994 г.), так и в конце (2014 г.). Отметим, что в начальный период экономического роста - с 1998 по 2002 г. - вес образовательных различий превышал 40\% (45\% в 2000 г.), а затем снизился до первоначальных значений. Фактор интенсивности занятости, занимающий второе место по вкладу в неравенство расходов, за рассматриваемый период увеличил свой вес практически в 2 раза (с 15,6\% в 1994 г. до $28,6 \%$ в 2014 г.). В сумме два признака, связанные с человеческим капиталом, объяснили 50\% неравенства расходов в 1994 г., затем наблюдался длительный период роста их совокупной объясняющей силы, которая в 2008 г. составила 65,3\%. Далее, до 2011 г. включительно происходил спад до $55,1 \%$, а затем опять рост до 64,5\% в 2014 г. Колебания доли неравенства, объясненной меритократическими факторами, связаны с адаптацией человеческого капитала к кризисным явлениям.

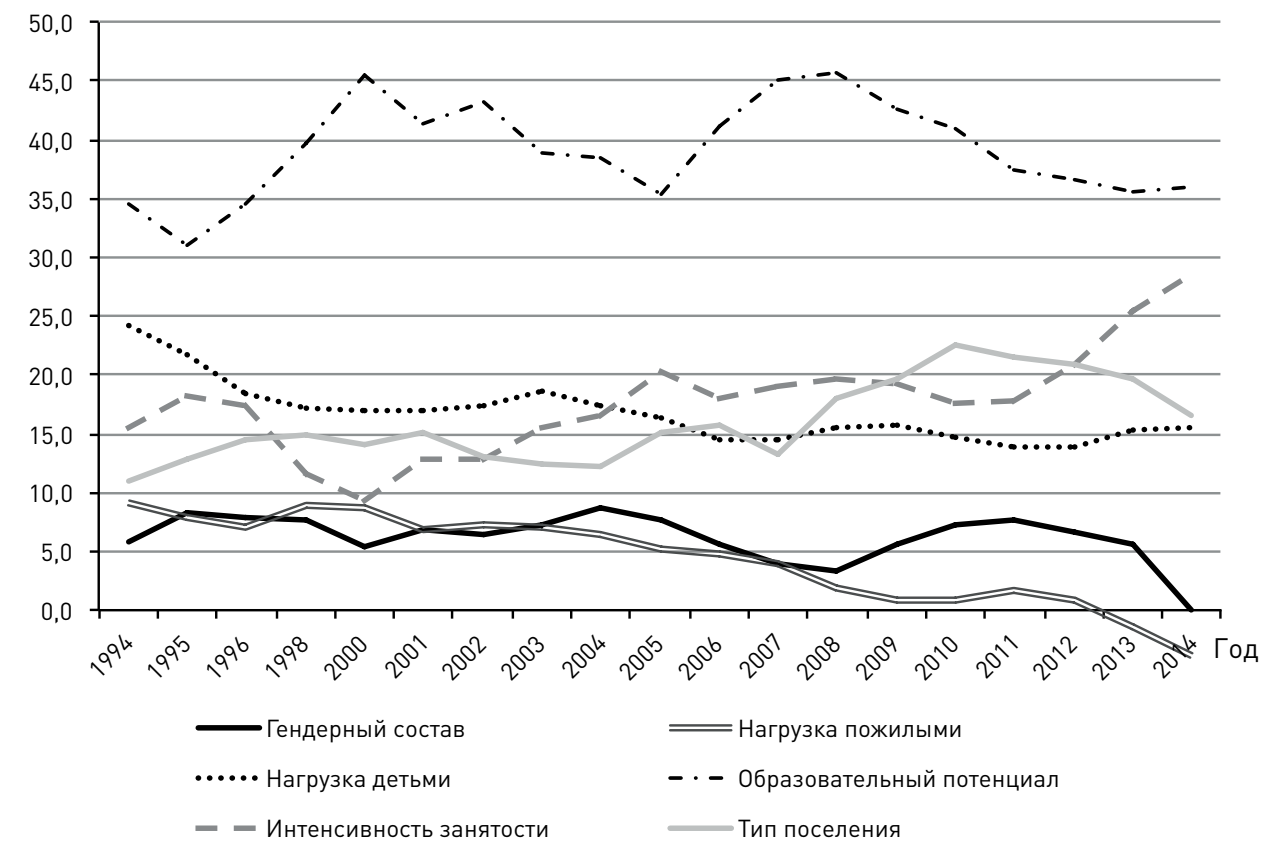

Pис. 9

Регрессионный анализ детерминант неравенства в 1994-2013 г2. (вклад признака в объяснение дисперсии душевых расходов, объясненной моделью), \%

Источник: расчеты авторов на перевзвешенных кроссекционных данных РМЭЗ-ВШЭ 1994-2014 гг.

Примечание. Сглаженный временной ряд. 
Совместный вклад в объяснение неравенства трех демографических признаков (гендерный состав, нагрузка пожилыми и детская нагрузка) упал с 39\% в 1994 г. до 18,8\% в 2013 г. При этом факт высокой концентрации в домохозяйстве лиц в возрасте старше 65 лет с 2013 г. перестал вносить положительный вклад в неравенство и принял на себя функцию выравнивания. Среди демографических факторов самым значимым, как и в случае анализа межгруппового неравенства, было соотношение в домохозяйстве числа детей в возрасте до 18 лет и взрослых.

Единственная аскриптивная характеристика домохозяйств, вес которой в рассматриваемый период увеличивался, - тип поселения. Ее вклад в неравенство рос до 2013 г., когда впервые за годы постсоветского развития крупные города пострадали больше остальных от последствий внешних экономических санкций и падения цен на нефть.

Таким образом, несмотря на то что Россия относится к странам с высоким неравенством, мы можем говорить о том, что теория В. Hee (Nee, 1989; Nee, Matthews, 1996) об увеличении значимости факторов человеческого капитала и снижении роли аскриптивных характеристик домохозяйств в рыночной экономике находит свое подтверждение на российских данных. Суммарный әффект уровня образования и интенсивности занятости домохозяйств за рассматриваемый период вырос в 1,3 раза, тогда как суммарный эффект трех демографических признаков упал в 2 раза. Одновременно с этим вес поселенческого фактора в объяснении неравенства душевых расходов, в отличие от других аскриптивных признаков, увеличился в 1,5 раза, что отражает структуру российской экономики. Декомпозиция общего неравенства на индивидуальном уровне на межгрупповое и внутригрупповое и регрессионный метод декомпозиции, позволяющий оценить совместный эффект различных факторов неравенства на микроуровне, показали значимое влияние на неравенство рентоориентированной экономики и недостаточно әффективную политику поддержки семей с детьми.

\section{ЛИТЕРАТУРА}

Гимпельсон В.Е., Капелюшников Р.И. (2008). Заработная плата в России. Эволюция и дифференциация / Под ред. В.Е. Гимпельсона, Р.И. Капелюшникова. М.: ВШЭ, 2008

Гимпельсон В.Е., Монусова Г.А. (2014). Восприятие неравенства и социальная мобильность [Электронный ресурс] (Серия WP3 «Проблемы рынка труда»).
Препринт Р3/2014/03. М.: НИУ ВШЭ; Изд. дом Высшей школы экономики.

Итоги сплошного федерального статистического наблюдения за деятельностью субъектов малого и среднего предпринимательства за 2010 год (2012). Т. 1. «Юридические лица и физические лица, осуществляющие предпринимательскую деятельность без образования юридического лица (сводные итоги)». М.: Федеральная служба государственной статистики, ИИЦ «Статистика России».

Модернизация России: социально-гуманитарные измерения (2011). / Под ред. Н.Я. Петракова. М., СПб.: Нестор-История, Российский государственный научный фонд, Российская академия наук.

Овчарова Л.Н. (2003). Рост неравенства в уровне материальной обеспеченности: объективная необходимость или несправедливое распределение?. В сб.: «Справедливые или несправедливые неравенства в современной России». Публикации Музея и общественного центра имени Андрея Сахарова. Серия «Теоретические проблемы прав человека». Вып. 3. М.: Референдум. С. 307-332.

Овчарова Л.Н. (2009). Теоретические и практические подходы к оценке уровня, профиля и факторов бедности: российский и международный опыт. Учреждение Российской академии наук, Институт социально-экономических проблем народонаселения РАН. М.: М-Студио.

Овчарова Л.Н. (2014). Динамика монетарных и немонетарных характеристик уровня жизни российских домохозяйств за годы постсоветского развития: аналитический доклад. М.: Фонд «Либеральная Миссия».

Пикетти Т. (2015). Капитал в 21 веке. М.: Ад Маргинем Пресс.

Попова Д.О. (2015). Динамика факторов неравенства в России на микроуровне в период 1994-2013 гг:: регрессионный анализ. Доклад на XVI Апрельской международной научной конференции «Модернизация экономики и общества». М.: НИУ ВШЭ.

Российский статистический ежегодник. 2015 (2015). Статистический сборник. М.: Росстат.

Российский статистический ежегодник. 2013 (2013). Статистический сборник. М.: Росстат.

Российский статистический ежегодник. 2011 (2011). Статистический сборник. М.: Росстат. 
Российский статистический ежегодник. 2010 (2010). Статистический сборник. М.: Росстат.

Социальное положение и уровень жизни населения России. 2015 (2015). Статистический сборник. М.: Росстат.

Социальное положение и уровень жизни населения России. 2014 (2014). Статистический сборник. М.: Росстат.

Социальное положение и уровень жизни населения России. 2013 (2013). Статистический сборник. М.: Росстат.

Социальное положение и уровень жизни населения России. 2012 (2012). Статистический сборник. М.: Росстат.

Социальное положение и уровень жизни населения России. 2011 (2011). Статистический сборник. М.: Росстат.

Социальное положение и уровень жизни населения России. 2010 (2010). Статистический сборник. М.: Росстат.

Социальное положение и уровень жизни населения России. 2009 (2009). Статистический сборник. М.: Росстат.

Социальное положение и уровень жизни населения России. 2008 (2008). Статистический сборник. М.: Росстат.

Социальное положение и уровень жизни населения России. 2007 (2007). Статистический сборник. М.: Росстат.

Социальное положение и уровень жизни населения России. 2006 (2006). Статистический сборник. М.: Росстат.

Социальное положение и уровень жизни населения России. 2005 (2005). Статистический сборник. М.: Росстат.

Социальное положение и уровень жизни населения России. 2004 (2004). Статистический сборник. М.: Росстат.

Социальное положение и уровень жизни населения России. 2003 (2003). Статистический сборник. М.: Росстат.

Социальное положение и уровень жизни населения России. 2002 (2002). Статистический сборник. М.: Росстат.

Социальное положение и уровень жизни населения России (2001). Статистический сборник. М.: Госкомстат России.

Социальное положение и уровень жизни населения России (2000). Статистический сборник. М.: Госкомстат России.

Социальное положение и уровень жизни населения России (1999). Статистический сборник. М.: Госкомстат России.

Социальное положение и уровень жизни населения России (1998). Статистический сборник. М.: Госкомстат России.

Социально-экономическое положение России в 2015 г. (2016). [Электронный ресурс] М.: Росстат. № ИМ-04-1/30-СД. Режим доступа: http://www.gks.ru/free_doc/ doc_2015/social/osn-12-2015.pdf, свободный. Загл. с экрана. Яз. рус. (дата обращения: июль 2016 г.).

Dabla-Norris E., Kochhar K., Ricka F., Suphaphiphat N., Tsounta E. (2015). Causes and Consequences of Income Inequality: A Global Perspective. International monetary fund. Strategy, Policy, and Review Department, Strategy, Policy, and Review Department.

Deaton A. (1997). The Analysis of Household Surveys: a Microeconometric Approach to Development Policy. Baltimore: Johns Hopkins University Press.

Gimpelson V.E., Treisman D. (2015). Misperceiving Inequality. National Bureau of Economic Research. Series NBER Working Paper 2015. No. 21174.

Kislitsina O.A. (2003). Income Inequality in Russia during Transition: How Can It Be Explained? Moscow: Economics Education and Research Consortium. P. 1-51.

Lukiyanova A. (2008). Structure and Distribution of Earning in Russia, 1994-2003 // Journal of Comparative Economic Studies. Vol. 4. P. 9-40.

Morduch J., Sicular T. (2002). Rethinking Inequality Decomposition, with Evidence from Rural China // Economic Journal. Vol. 112. P. 93-106.

Nee V. (1989). A Theory of Market Transition: from Redistribution to Markets in State Socialism // American Sociological Review. Vol. 54. P. 663-681.

Nee V., Matthews R. (1996). Market Transition and Societal Transformation in Reforming State Socialism / / Annual Review of Sociology. Vol. 22. P. 401-435.

OECD (2013). OECD Framework for Statistics on the Distribution of Household Income, Consumption and Wealth. [Электронный pecypc] OECD Publishing. P. 174-175. Режим доступа: http://www.oecd.org/ statistics/302013041e.pdf, свободный. Загл. с экрана. Яз. англ. (дата обращения: июль 2016 г.).

OECD (2015). In It Together: Why Less Inequality BenefitsAll. [Электронныйресурс] OECD Publishing, Paris. Режим доступа: http: / / dx.doi.org/10.1787/9789264235120-en, свободный. Загл. с экрана. Яз. англ. (дата обращения: июль 2016 г.).

Popova D. (2013). Country Note: Russian Federation. Civil 20 Proposals for Strong, Sustainable, Balanced and Inclusive Growth. M.: UNDP. 
Shorrocks A. (1984). Inequality Decomposition by Population Subgroups / / Econometrica. Vol. 52(6). P. 1369-1386.

Shorrocks A.F. (1980). The Class of Additively Decomposable Inequality Measures // Econometrica. Vol. 48(3). P. 613-625.

Stiglitz J.E. (2012). The Price of Inequality: How Today's Divided Society Endangers Our Future. New York: W.W. Norton \& Company.

Yemtsov R. (2003). Quo Vadis? Inequality and Poverty Dynamics Across Russian Regions. WIDER discussion paper No. 2003/67. Helsinki: United Nations University, World Institute for Development Economics $1609-5774$.

Поступила в редакиию 10 июля 2016 года

REFERENCES (with English translation or transliteration)

Dabla-Norris E., Kochhar K., Ricka F., Suphaphiphat N., Tsounta E. (2015). Causes and Consequences of Income Inequality: A Global Perspective. International monetary fund. Strategy, Policy, and Review Department, Strategy, Policy, and Review Department.

Deaton A. (1997). The Analysis of Household Surveys: a Microeconometric Approach to Development Policy. Baltimore: Johns Hopkins University Press.

Gimpelson V.E., Kapeliushnikov R. (2008). Wages in Russia: Evolution and Differentiation. Gimpelson V.E., Kapeliushnikov R. (ed.). Moscow: SU-HSE Publishing House (in Russian).

Gimpelson V.E., Monusova G. (2014). Perception of Inequality and Social Mobility. Preprint P3/2014/03. Moscow: SU-HSE Publishing House (in Russian).

Gimpelson V.E., Treisman D. (2015). Misperceiving Inequality. National Bureau of Economic Research. Series NBER Working Paper No. 21174.

Kislitsina O.A. (2003). Income Inequality in Russia during Transition: How Can It Be Explained? Moscow: Economics Education and Research Consortium, 1-51.

Lukiyanova A. (2008). Structure and Distribution of Earning in Russia, 1994-2003. Journal of Comparative Economic Studies 4, 9-40.

Modernization of Russia: Social and Humanitarian Measurements (2011). N.Ya. Petrakov (ed.). Moscow, Saint Petersburg: NestorHistoria (in Russian).
Morduch J., Sicular T. (2002). Rethinking Inequality Decomposition, with Evidence from Rural China. Economic Journal 112, 93-106.

Nee V. (1989). A Theory of Market Transition: from Redistribution to Markets in State Socialism. American Sociological Review 54, 663-681.

Nee V., Matthews R. (1996). Market Transition and Societal Transformation in Reforming State Socialism. Annual Review of Sociology 22, 401-435.

OECD (2013). OECD Framework for Statistics on the Distribution of Household Income, Consumption and Wealth. OECD Publishing, 174-175. Available at: http://www. oecd.org/statistics/302013041e.pdf (accessed: July 2016).

OECD (2015). In It Together: Why Less Inequality Benefits All. OECD Publishing, Paris. Available at: http://dx.doi. org / $10.1787 / 9789264235120$-en (accessed: July 2016).

Ovcharova L.N. (2003). Increasing Material Security Inequalities: an Objective Necessity or an Unfair Distribution? Fair and Unfair Inequalities in Modern Russia. Sakharov Center Publications, Theoretical Problems of Human Rights, Series. Moscow: Referendum, 307332 (in Russian).

Ovcharova L.N. (2009). Theoretical and Practical Approaches to the Evaluating the Level, the Profile and Factors of Poverty Russian and International Experiences. Institute for Socio-Economic Studies of Population, Russian Academy of Sciences. Moscow: M-Studio (in Russian).

Ovcharova L.N. (2014). Dynamics of Russian Households Monetary and Non-monetary Features: Analytical Report. Moscow: Fond Liberalnaya Missiia (in Russian).

Piketty T. (2015). Capital in the Twenty-First Century. Moscow: As Marginem Press (in Russian).

Popova D. (2013). Country Note: Russian Federation. Civil 20 Proposals for Strong, Sustainable, Balanced and Inclusive Growth. M.: UNDP.

Popova D.O. (2015). Inequality factors Dynamics in Russia at Microlevel in 1994-2013: Regression analysis. Report at the XVI April International Academic Conference on Economic and Social Development. Moscow: SU-HSE Publishing House (in Russian).

Results of the Complete Federal Statistic Survey of SMEs in 2010 (2012). Vol. 1. Legal Entities and Individuals Not Forming a Legal Entity 
and Undertaking Entrepreneurial Activity in 2010. Moscow: Federal State Statistics Service, Information \& Publishing Center Statistics of Russia (in Russian).

Shorrocks A. (1984). Inequality Decomposition by Population Subgroups. Econometrica 52(6), 1369-1386.

Shorrocks A.F. (1980). The Class of Additively Decomposable Inequality Measures // Econometrica 48(3), 613-625.

Social and Economic Situation in Russia 2015. (2016). Moscow: Rosstat. No. IM-04-1/30SD. Available at: http://www.gks.ru/ free_doc/doc_2015/social/osn-12-2015. pdf. (accessed: July 2016, in Russian).

Social Situation and Living Standards of the Russian Population. 2015 (2015). Statistical Handbook. Moscow: Rosstat (in Russian).

Social Situation and Living Standards of the Russian Population. 2014 (2014). Statistical Handbook. Moscow: Rosstat (in Russian).

Social Situation and Living Standards of the Russian Population. 2013 (2013). Statistical Handbook. Moscow: Rosstat (in Russian).

Social Situation and Living Standards of the Russian Population. 2012 (2012). Statistical Handbook. Moscow: Rosstat (in Russian).

Social Situation and Living Standards of the Russian Population. 2011 (2011). Statistical Handbook. Moscow: Rosstat (in Russian).

Social Situation and Living Standards of the Russian Population. 2010 (2010). Statistical Handbook. Moscow: Rosstat (in Russian).

Social Situation and Living Standards of the Russian Population. 2009 (2009). Statistical Handbook. Moscow: Rosstat (in Russian).

Social Situation and Living Standards of the Russian Population. 2008 (2008). Statistical Handbook. Moscow: Rosstat (in Russian).

Social Situation and Living Standards of the Russian Population. 2007 (2007). Statistical Handbook. Moscow: Rosstat (in Russian).

Social Situation and Living Standards of the Russian Population. 2006 (2006). Statistical Handbook. Moscow: Rosstat (in Russian).

Social Situation and Living Standards of the Russian Population. 2005 (2005). Statistical
Handbook. Moscow: Rosstat (in Russian).

Social Situation and Living Standards of the Russian Population. 2004 (2004). Statistical Handbook. Moscow: Rosstat (in Russian).

Social Situation and Living Standards of the Russian Population. 2003 (2003). Statistical Yearbook. Moscow: Rosstat (in Russian).

Social Situation and Living Standards of the Russian Population. 2002 (2002). Statistical Yearbook. Moscow: Rosstat (in Russian)..

Social Situation and Living Standards of the Russian Population. 2001 (2001). Statistical Yearbook. Moscow: Rosstat (in Russian).

Social Situation and Living Standards of the Russian Population. 2000 (2000). Statistical Yearbook. Moscow: Goskomstat of Russia (in Russian).

Social Situation and Living Standards of the Russian Population. 1999 (1999). Statistical Yearbook. Moscow: Goskomstat of Russia (in Russian).

Social Situation and Living Standards of the Russian Population. 1998 (1998). Statistical Yearbook. Moscow: Goskomstat of Russia (in Russian).

Statistical Yearbook of Russia. 2010 (2010). Statistical Handbook. Moscow: Rosstat (in Russian).

Statistical Yearbook of Russia. 2011 (2011). Statistical Handbook. Moscow: Rosstat (in Russian).

Statistical Yearbook of Russia. 2013 (2013). Statistical Handbook. Moscow: Rosstat (in Russian).

Statistical Yearbook of Russia. 2015 (2015). Statistical Handbook. Moscow: Rosstat (in Russian).

Stiglitz J.E. (2012). The Price of Inequality: How Today's Divided Society Endangers Our Future. New York: W.W. Norton \& Company.

Yemtsov R. (2003). Quo Vadis? Inequality and Poverty Dynamics Across Russian Regions. WIDER discussion paper No. 2003/67. Helsinki: United Nations University, World Institute for Development Economics $1609-5774$.

Received 10 July 2016 


\title{
L.N. Ovcharova
}

National Research University Higher School of Economics, Moscow, Russia

D.O. Popova

National Research University Higher School of Economics, Moscow, Russia

A.M. Rudberg

National Research University Higher School of Economics, Moscow, Russia

\section{Decomposition of Income Inequality in Contemporary Russia $^{6}$}

Abstract. Over the last 25 years, Russia has passed from the group of countries distinguished by low levels of income inequality to the group distinguished by high ones. The macroeconomic analysis shows that this process is due to the differences in salaries, the weak equalizing effect of social transfers and new sources of income such as the income from property and of business activity. We have a poor understanding of the factors determining this inequality at the household level so far. Decomposition of equivalised household expenditure inequality into inter- and intra-groups using cross-sectional data (RLMS-HSE, 1994-2014) shows that during the whole research period one of the most significant factors of intergroup inequality is region of residence. During periods of high economic growth the significance of education and intensity of employment increased in intergroup inequality; however, during the period of economic stagnation the intergroup differentiation of educational potential began to decrease. Despite the important population policy aimed to increase the birth rate, children in families have become the most significant factor of intergroup inequality for the last years. A regression analysis of the determinants of inequality, which allows us to estimate the contribution of each factor to the model dispersion of per capita expenditure allows us to draw the conclusion that meritocratic factors explain a majority of observed inequality. The contribution of the child-burden factor to total inequality did not change during the past ten years, and at the same time, the inequality-decreasing effect of the presence of pensioners in households has continuously increased.

Keywords: income and wages inequality, wealth and poverty, human capital.

JEL Classification: D6, I3, J3, N00, P36.

\author{
В.Е. Гимпельсон \\ ЦеТИ НИУ ВШЭ, Москва
}

\section{Отраслевые сАвиги и межотраслевое неравенство}

\begin{abstract}
Аннотация. В статье обсуждается вопрос о влиянии отраслевого деления на неравенство в заработной плате в России в начале XXI в. Это влияние определяется отраслевой структурой занятости, уровнем отраслевых премий и внутриотраслевой дифференциацией уровней заработной платы. Расчеты, основанные на различных данных Росстата, показывают, что данные факторы способствовали снижению неравенства. В отраслевой структуре сокращалась доля в общей занятости отраслей, имеющих самые высокие и самые низкие заработные платы, тем самым сжимая с обеих сторон распределение заработных плат. Уровни оплаты в отраслях-лидерах и отраслях- аутсайдерах приближались к средним по всей экономике. В то же время внутриотраслевое неравенство, измеряемое коэффициентом Джини, также сокращалось. Наблюдаемая динамика межотраслевого неравенства в среднесрочной перспективе может сохраниться. Снижение мировых цен на сырье и энергоносители будет отрицательно влиять на возможности соответствующих предприятий повышать оплату труда, тем самым сжимая относительные заработные платы. То же самое, по-видимому, будет происходить и в финансовом секторе, на который серьезно повлиял текущий кризис. Если повышающее давление на заработную плату в бюджетных отраслях не исчезнет, то относительные заработные платы в них будут расти, а доля в занятости - падать, что также создаст выравнивающий эффект.
\end{abstract}

Ключевые слова: заработная плата, неравенство, межотраслевая дифференииаиия. Классификация JEL: J21, J31.

\footnotetext{
6 The publication has been prepared with the financial assistance of the Center for Basic Research of National Research University Higher School of Economics.
} 